\title{
Self-documentary in the emergency department: Perspectives on patients recording their own procedures
}

\author{
Taofiq Oyedokun, $\mathrm{MBChB}^{*}$; Andrew Donauer, $\mathrm{MS}^{\dagger}$; James Stempien, $\mathrm{MD}^{*}$; Shari McKay, $\mathrm{MA}^{\ddagger}$
}

\begin{abstract}
CLINICIAN'S CAPSULE
What is known about the topic?

Taking photographs and educational videos are common in emergency departments (EDs), but little research exists about patients recording their own procedures.

What did this study ask?

What are patients' reasons for video recording in the ED and the views of patients and clinicians toward this practice?

What did this study find?

Patients were in favour of ED video recording, whereas clinicians were not. Patients' reasons and clinicians' caveats for recording are provided.

Why does this study matter to clinicians?

This study provides a basis for the development of policy concerning video recording by patients in the ED.
\end{abstract}

\section{ABSTRACT}

Objectives: Patients often bring their smartphones to the emergency department (ED) and want to record their procedures. There was no clear ED recording policy in the Saskatoon Health Region nor is there in the new Saskatchewan Health Authority. With limited literature on the subject, clinicians currently make the decision to allow/deny the request to record independently. The purpose of this study was to examine and compare patient and clinician perspectives concerning patients recording, in general, and recording their own procedures in the ED.

Methods: Surveys were developed for patients and clinicians with respect to history and opinions about recording/being recorded. ED physicians and nurses, and patients $>17$ years old who entered the ED with a laceration requiring stitches were recruited to participate; 110 patients and 156 staff responded.

Results: There was a significant difference between the proportion of patients (61.7\% [66/107]) and clinicians $(28.1 \%$ [41/146]) who believed that patients should be allowed to video record their procedure. There was also a significant difference between clinicians and patients with regard to audio recording, but not "selfies" (pictures). However, with no current policy, $47.8 \%(66 / 138)$ of clinicians said that they would allow videos if asked, with caveats about staff and patient privacy, prior consent, and procedure/patient care.

Conclusion: Contrary to patients' views, clinicians were not in favour of allowing audio or video recordings in the ED. Concerns around consent, staff and patient privacy, and legal issues warrant the development of a detailed policy if the decision is made in favour of recording.

\section{RÉSUMÉ}

Objectifs: Les patients emportent souvent leur téléphone intelligent au service des urgences (SU) et veulent enregistrer les interventions faites sur leur personne. II n'existait pas de politique claire sur les enregistrements dans les SU, dans I'ancienne région sanitaire de Saskatoon, pas plus qu'il n'existe actuellement dans la nouvelle région sanitaire de la Saskatchewan. Disposant de peu de documentation sur le sujet, les cliniciens acceptent ou refusent, à leur gré, les demandes d'enregistrement. L'étude visait donc à examiner et à comparer les points de vue des patients et des cliniciens sur les enregistrements effectués par les patients en général, et sur celui des interventions pratiquées sur ces derniers.

Méthode: Des questionnaires d'enquête ont été élaborés à l'intention des patients et des cliniciens sur les expériences antérieures d'enregistrement et, pour ces derniers, sur le fait d'être enregistrés, ainsi que sur l'opinion des uns et des autres sur le sujet. Des médecins et des infirmières/infirmiers travaillant au SU ainsi que des patients âgés de plus de 17 ans ayant subi des lacérations qui nécessitaient des points de suture ont été invités à participer à l'étude : 110 patients et 156 membres du personnel ont accepté.

Résultats: II y avait un écart significatif entre la proportion de patients $(61,7 \%$; 66/107) et celle de cliniciens $(28,1 \%$; 41/146) qui étaient d'avis que les premiers devraient avoir la permission de faire des enregistrements vidéo des interventions effectuées sur leur personne; il en allait de même pour les

From the *Department of Emergency Medicine, University of Saskatchewan, Saskatoon, SK; †College of Medicine, University of Saskatchewan, Saskatoon, SK; and ¥Academic Family Medicine, Research Division, University of Saskatchewan, Saskatoon, SK

Correspondence to: Andrew (AJ) Donauer, 431 David Knight Lane, Saskatoon, SK S7K 5M1; Email: aj.donauer@usask.ca 
enregistrements audio des interventions, mais pas en ce qui concerne les égoportraits (photos de soi-même). Toutefois, devant l'absence de politique en la matière, $47,8 \%$ (66/138) des cliniciens accepteraient les enregistrements vidéo si on le leur demandait, mais attireraient l'attention sur le respect de la vie privée tant du personnel que des autres patients, avant de donner leur consentement et d'effectuer l'intervention ou de fournir des soins.

Conclusion: Contrairement aux patients, les cliniciens se sont montrés défavorables aux enregistrements audio ou vidéo effectués par les premiers au SU. Des préoccupations relatives au consentement, de même qu'au respect de la vie privée des personnels médical et infirmier et des autres patients, ainsi que des questions d'ordre juridique justifient l'élaboration d'une politique détaillée en la matière si les autorités devaient prendre une décision en faveur des enregistrements.

Keywords: Audiovisual recordings, emergency department, privacy, social media, smart phones

\section{INTRODUCTION}

Smartphones are now ubiquitous in our society, and, as the technology improves and their use increases and is compounded by the rapid growth of social media, ${ }^{1-4}$ it is no longer an uncommon practice for patients and their family members or friends to attempt to capture the patient-physician interaction in the emergency department (ED). ${ }^{4-7}$ In 2015, almost $73 \%$ of Canadians over the age of 18 owned a smartphone ${ }^{3}$; therefore, it was expected that many patients would indicate that they owned a device capable of recording, which was the case for our study $(81.8 \%)$. Currently, public policy on video recording in the healthcare setting is governed by provincial legislation and varies across Canada at each hospital or $\mathrm{ED}{ }^{5,8,9}$ Although studies have looked at the use of video recording for educational and quality assurance purposes, as well as the value of recording the patient/ clinician interaction in clinical settings, ${ }^{10,11}$ in our review of the literature, we found no studies quantifying how often patients are recording videos in the ED. We also found no studies detailing why patients want to record videos, or what the attitudes and practices of staff are concerning this practice.

In EDs within the Saskatchewan Health Authority, patients have been allowed to take pictures before, during, or after treatment of their injury, at the discretion of the staff, and as long as no identifying data or faces are included. The request to video record is increasing, which has generated some controversy among staff, who have concerns about patient and staff confidentiality and covert recording. ${ }^{12-14}$ With no current policy in place, the purpose of this study was to examine and compare patient and clinician (both physicians' and nurses') perspectives regarding patients video recording their own procedures in the ED and to lay the groundwork for further research and policy development regarding video recording and recording, in general, by patients in the ED.

\section{METHODS}

\section{Design}

Patients and clinicians in the three urban EDs in Saskatoon, Saskatchewan, were asked to complete a short survey about video recording procedures and recording, in general. Based on an informal opinion poll of ED physicians before the study and looking at the statistics, we estimated that 3 to 6 patients would require sutures per day in Saskatoon EDs. Over the course of 4 to 6 weeks, this gave us a target goal of 100 to 200 patients. Patients and clinicians were recruited via a convenience sample of willing and eligible participants.

Patients were recruited to participate by on-shift nurses, physicians, and members of the research team (TO, AD, JS) based upon a triage complaint of laceration, potentially requiring sutures. These recruiters were briefed by the research team to both distribute surveys and direct patients where to deposit the completed surveys (into secure collection boxes behind the triage desk). Patient surveys were consistently distributed to eligible patients before their procedure in the waiting room or in the procedure room at an appropriate time, so as not to interfere with care. Members of the research team (TO, $\mathrm{AD}, \mathrm{JS}$ ) frequented the $\mathrm{ED}$ (four to five times per week) to maintain awareness of the study for working physicians and nurses throughout the study period.

Additionally, staff surveys were administered in person or placed in physician and nurse lounges and in physician hospital mailboxes. Secure collection boxes were placed in the staff lounges and behind the triage desk at each site, and these were emptied weekly.

\section{Survey development}

An internal focus group met to discuss and develop the survey consisting of both closed and open-ended 
questions. The questions were then pilot-tested with a small group of patients and clinicians, which resulted in satisfactory responses, prior to full distribution to all study sites. Ethics approval was obtained from the University of Saskatchewan's Research Ethics Board, and operational approval was obtained from the Saskatoon Health Region prior to data collection. As indicated in the information provided to both patients and staff, consent was implied upon completion of the survey after the respondent read the consent/information sheet.

\section{Inclusion and exclusion criteria}

Patients $>17$ years of age entering any of the Saskatoon EDs with at least one laceration requiring sutures were invited to participate. Patients without the capacity to consent or with life and/or limb-threatening injuries were excluded from the study. ED physicians and nurses were also recruited to participate. Unit clerks, security personnel, and any other non-medical staff were excluded from the study because they are not directly involved in the clinical care of patients.

\section{Data analysis}

Descriptive statistics were calculated for age, sex, and profession as well as the dichotomous variables related to experiences with recording and whether recording should be allowed. The chi square test was used to examine differences between groups for categorical variables, substituting the Fisher exact test when more than $20 \%$ of expected cell sizes were less than 5 . Sufficient data were collected from the open-ended questions to quantify the responses for analysis. All data were analysed using SPSS (v. 23.0).

\section{RESULTS}

Over the 2-month collection period, 92.4\% (110/119) of patients, $62.7 \%(37 / 59)$ of physicians, and $47.6 \%$ (119/250) of nurses responded to the survey. The participant demographics are outlined in Table 1, in addition to some background patient data, which were collected from the survey. Although responses were not directly correlated with the participants' ages, our results did reveal that $50 \%$ of patients were $<35$ years old, and $75 \%$ of patients were $<50$ years with a mean age of 41 years. Additionally, patients and physicians were predominantly male, whereas nurses were predominantly female.

With regard to video recordings of procedures, $35.3 \%(42 / 119)$ of nurses and $83.8 \%(31 / 37)$ of physicians indicated that, in the past, they had experienced a patient who wanted to record his or her procedure, and $55.9 \%$ (19/34) of the physicians and 33.9\% (19/56) nurses had allowed that patient to record. Proportionately, $42.9 \%(15 / 35)$ of physicians and $49.5 \%(51 / 103)$ of nurses indicated that if the patient asked to take a video of the procedure, they would allow the patient to do so.

Patients and clinicians were also asked about recording, in general. These results are presented in Table 2. Whereas $61.7 \%(66 / 107)$ of patients were in favour of allowing video recordings by patients in the ED, only $28.1 \%$ (41/146) of clinicians were in favour of allowing it $(p=0.000)$. Concerning allowing audio recordings in the $\mathrm{ED}, 48.6 \%(51 / 105)$ of patients were in favour of it, whereas only $19.0 \%(28 / 147)$ of clinicians were in favour of audio recording $(p=0.000)$. There were no significant differences between nurse and physician responses. There was a statistically significant difference between clinician and patient

\section{Table 1. Participant demographics}

\begin{tabular}{llll} 
& Patients & Nurses & Physicians \\
\hline Number of participants & 110 & 119 & 37 \\
Gender & $70 \%$ male & $85.7 \%$ female & $75.7 \%$ male \\
Age (years) & 40.57 & 35.08 & $(\mathrm{SD}=10.3)$ \\
& $(\mathrm{SD}=20.0)$ & - & - \\
Own a recording device & $81.8 \%$ & - & - \\
Received sutures previously & $80 \%$ & - & - \\
Admit to taking a video in ED previously & $5.5 \%$ & - & - \\
Considered video recording procedure at time of survey & $30.8 \%$ & &
\end{tabular}


Patients recording their own procedures in the ED

Table 2. Proportion of patients and clinicians responding "yes" to recordings in the ED

\begin{tabular}{lcccc} 
& Patients & Nurses & Physicians & $p$-value \\
\hline Patients should be: & & & & \\
$\quad$ Allowed to take videos & $61.7 \%(66 / 107)$ & $27.3 \%(30 / 110)$ & $30.6 \%(11 / 36)$ & $p=0.000$ \\
Allowed to take audios & $48.6 \%(51 / 105)$ & $18.9 \%(21 / 111)$ & $19.4 \%(7 / 36)$ & $p=0.000$ \\
Allowed to take "selfies" (pictures) & $55.1 \%(59 / 107)$ & $54.1 \%(60 / 111)$ & $48.6 \%(17 / 35)$ & $p=0.793$
\end{tabular}

responses concerning video and audio recordings, but there was no significant difference between the groups for "selfies" (pictures).

Physicians and nurses were asked: "Why do you think patients would want to video a procedure?" Likewise, patients were asked: "If you were to take a video of the procedure (suturing of your laceration), please explain your reason for doing so (what would you do with the video?).” Responses to these questions were grouped into themes with results presented in Table 3 .

Physicians and nurses were asked: "If a patient asked you whether he or she could take a video of a procedure (i.e., the suturing of a laceration), would you allow it? (yes or no) Why or why not?" The reasons that they provided have been grouped into themes and are presented in Table 4. A more detailed discussion will follow. Note that participants may have had more than one type of comment per question.

\section{DISCUSSION}

Although patient privacy is highly regulated by provincial legislation, much of the burden for privacy is placed on clinicians, leaving patients with relatively few regulations to follow. ${ }^{5,7,8}$ This situation provides patients with greater freedom to record a patient-physician interaction. Current policy on ED video recording within the Saskatchewan Health Authority leaves the decision to record to the physician's discretion. ${ }^{1,5}$ Patient privacy and autonomy serve as primary concerns in healthcare, and therefore, in the ED, the privacy and autonomy of other patients and staff members are also a major issue that must be addressed. Video recording policies must be developed in a hospital-specific manner because this is a highly controversial topic, and opinions and practices vary across the country.

Our study found that patients were more in favour of being allowed to record, regardless of the type of media (video, audio, or "selfies"). This could indicate a lack of awareness on their part of the different adverse outcomes that might arise, ${ }^{7}$ in particular, for video and audio

\begin{tabular}{|c|c|c|c|}
\hline & $\begin{array}{l}\text { Patients } \\
(n=55)\end{array}$ & $\begin{array}{l}\text { Clinicians } \\
(\mathrm{n}=139)\end{array}$ & $p$-values \\
\hline Interest & $29.1 \%(16)$ & $20.9 \%(29)$ & 0.22 \\
\hline $\begin{array}{l}\text { Popularity/bragging } \\
\text { rights }\end{array}$ & $9.1 \%(5)$ & $23.7 \%(33)$ & 0.02 \\
\hline Sharing & $43.6 \%(24)$ & $65.5 \%(91)$ & 0.005 \\
\hline Legal & $3.6 \%(2)$ & $22.3 \%(31)$ & 0.002 \\
\hline Unhappy with care & $0 \%(0)$ & $4.3 \%(6)$ & 0.19 \\
\hline Memento & $38.2 \%(21)$ & $26.6 \%(37)$ & 0.11 \\
\hline Record of care & $12.7 \%(7)$ & $11.5 \%(16)$ & 0.81 \\
\hline
\end{tabular}

Table 4. Proportion of clinicians in favour of allowing or not allowing video recording

\begin{tabular}{lccc} 
& $\begin{array}{c}\text { In favour } \\
(\mathrm{n}=66)\end{array}$ & $\begin{array}{c}\text { Not in favour } \\
(\mathrm{n}=67)\end{array}$ & p-values \\
\hline $\begin{array}{l}\text { Endorse video } \\
\quad \text { recording }\end{array}$ & $33.3 \%(22)$ & 0 & $<0.0001$ \\
Reject video recording & 0 & $10.4 \%(7)$ & 0.01 \\
Legal reasons & 0 & $10.4 \%(7)$ & 0.01 \\
Intent of patient & $3 \%(2)$ & $17.9 \%(12)$ & 0.005 \\
Privacy & $54.5 \%(36)$ & $61.2 \%(41)$ & 0.44 \\
Pressure on clinician & $4.5 \%(3)$ & $14.9 \%(10)$ & 0.04 \\
Effect on procedure & $10.6 \%(7)$ & $7.5 \%(5)$ & 0.53 \\
Consent & $15.2 \%(10)$ & $4.5 \%(3)$ & 0.04
\end{tabular}

recording in the ED setting. Physicians and nurses differed significantly from patients in their support for both video and audio recordings. These clinicians included numerous comments about confidentiality and anonymity related to the lack of privacy in the treatment areas of the ED, which could lead to inadvertent videos or audios of other patients and staff and therefore to violations in patient and staff confidentiality.

Of the physicians that participated in the study, over $80 \%$ indicated that they had a patient request to video record in the past. The proportion of clinicians who had 
received a request was significantly higher for physicians than for nurses, most likely because physicians would have been the recipients of the request as the person performing the procedure. Our survey also revealed that $30.8 \%$ of patients self-reported that they had contemplated taking a video of their procedure on the day of the survey.

Most often, responses to the question as to why clinicians would or would not allow recording were caveats and concerns, rather than explicit reasons for or against. Of the 66 clinicians who indicated that they would allow patients to video, only 22 provided statements that gave a reason for endorsing the choice. These were mostly in support of the patients' right to video their own body or to have a record of care. Of those who were not in favour of allowing patient videos, some simply found it inappropriate, whereas others indicated concerns about legal action and the inability to guarantee the intended use for the video, as well as lack of control over the distribution.

With regard to reasons for recording, patients and clinicians reported with similar frequency: "interest by patient" and "memento keeping and/or record of care," and both reported "sharing" as a reason, although clinicians at a higher rate. Neither patients nor clinicians indicated that the video recording would result in better patient care. Patients mostly said share with friends and family, whereas clinicians more often specified social media, indicating a heightened awareness of the potential for wider dissemination. At the same time, more clinicians suggested that it may be because the procedure would be seen as novel or "cool" for the patients, and the recording would be shared to boost self-image. In addition, clinicians also suggested that patients might record for potential legal action or as retribution if they were unhappy with care, giving rise to the concerns raised with respect to knowing the patients' true intent when deciding to permit video recordings.

Both groups, who answered either "yes" or "no" to allowing a patient to take a video, had concerns about privacy and pressure on the clinician, as well as issues related to the procedure. Outright objections included the possibility of recording the faces of staff and patients as well as audio recording of other patients. Others indicated that it was fine with these restrictions: "not my face," "no faces," "no audio," or "no genitals" indicating the need for a policy fully defined in these areas. The concern around audio recording suggests that a policy should not be limited to video recording, because audio recording might occur without the video, and has the potential to be easily conducted covertly. Many clinicians indicated the importance of obtaining consent prior to making a recording. It was unexpected that none would bring up the issue of covert recording; however, it may be that regulating the need for consent might discourage covert recording. Many clinicians indicated the importance of obtaining consent prior to making a recording. Some clinicians did not want to agree to have the procedure videotaped because of performance anxiety. Although some literature has addressed these concerns with learners, ${ }^{15,16}$ we have found no research as to the effects of being recorded in the ED. Some clinicians expressed concern that it would be fine if it did not interfere with the procedure; others indicated that agreement would depend on the nature of the procedure.

In keeping with the suggestion that a policy be developed for public and private spaces within the medical setting, ${ }^{5,7}$ our study revealed the following information (under the premise that a complete ban of video recording is not feasible in a given situation). We believe that it would be most appropriate to develop a policy for private spaces only allowing the video recording of procedures in ED rooms meeting a specific set of criteria that the room has walls and a closed door, no faces or genitals or confidential personal health information are shown (or heard), the video focuses on the procedure, and the verbal consent of all parties present has been obtained. Video or audio recording of any type in a public space should be prohibited primarily due to the lack of privacy and consent by other individuals who may be shown or heard in the recording.

Further opportunities for research in this area, including the development of a succinct policy on patient video recording in the ED, should further tailor the discussion towards specific conditions that must be met to maintain privacy and confidentiality. This should include addressing the time constraints in the $\mathrm{ED}$, because additional procedures, such as obtaining consent and verifying the content of videos, could add considerable time to a patient's visit. In addition, patients' autonomy to video record their own medical procedures as a means of personal documentation must be further examined from a legal standpoint, specifically related to feasibility in a busy ED and consistency between different health regions. With the merging of the province into a single health authority, it needs to 
be determined whether urban and rural EDs would work under the same policy or would require different procedures. ${ }^{17}$ Although it was not addressed in this study, it would be interesting to see whether there were any differences in findings based on gender and age categories. Finally, it would be interesting to explore how patient perspectives may differ concerning "teaching videos" in the ED versus patient-recorded videos.

\section{LIMITATIONS}

\section{Sample size}

A reasonable sample of clinicians was obtained for this study, but the patient group was limited in size and limited to a specific complaint. Although issues around patient care did not arise as reasons for the video, it may be that inviting participants with a broader array of complaints will contribute to the discussion as to the necessity of recordings and circumstances in which they might be relevant to better care.

\section{Self-reporter bias}

Participants self-reported their answers, so there is the potential that participants may not have answered honestly or remembered events correctly. However, the confidential nature of the survey should have dispelled any reasons for participants to fabricate answers.

\section{Location bias}

This study was completed in urban EDs. There is the potential that we could see different results in a rural setting. For example, with a smaller community that is less formal, perhaps physicians would be more inclined to allow patients to video or audio record procedures.

\section{Sampling bias}

Because our study included a convenience sample of patients and clinicians, the study population may not be completely representative of the entire population. However, our return rate was high enough to compensate for this shortcoming.

\section{CONCLUSION}

Although most patients would like to record procedures performed on them, most clinicians do not support this activity in the ED. Because less than half of clinicians would approve, and given the extent of their caveats and concerns, careful consideration must be given to confidentiality and legal issues when developing a policy. Further research should be done to establish a proper policy on video recording in the ED that is relevant to each hospital. Furthermore, national professional organizations like the Canadian Medical Association, Canadian Association of Emergency Physicians, and College of Family Physicians of Canada could develop policies to guide their members. At this time, we recommend that video or audio recording of any type in a public space should be prohibited without privacy and consent by other individuals who may be shown or heard in the recording. Recordings should be allowed only in private spaces in the ED that meet a specific set of criteria: the room has walls and a closed door, no faces or genitals or confidential personal health information are shown (or heard), the video focuses solely on the procedure, and the verbal consent of all parties present has been obtained.

Financial support: Andrew Donauer (medical student) received a scholarship as part of the Dean's Summer Research Fund at the University of Saskatchewan, College of Medicine.

Competing interests: None declared.

\section{REFERENCES}

1. Lyons R, Reinisch C. The legal and ethical implications of social media in the emergency department. Adv Emerg Nurs 7 2013;35(1):53-6.

2. Boulos MN, Wheeler S, Tavares C, et al. How smartphones are changing the face of mobile and participatory healthcare: an overview, with example from eCAALYX. Biomed Eng Online 2011;10(1):14.

3. Canadian Radio-Television and Telecommunications Commission (CRTC). Communications monitoring report; 2016. Available at: http://www.crtc.gc.ca/eng/publications/reports/ PolicyMonitoring/2016/cmr.pdf (accessed 12 December 2017).

4. Tan L, Hu W, Brooker R. Patient-initiated camera phone images in general practice: a qualitative study of illustrated narratives. Br 7 Gen Pract 2014;64(622):e290-4.

5. CFEM. What to do when a patient wants to record a patientphysician interaction in the emergency department; 2017. Available at: https://doi.org/10.1017/cem.2017.23 Epub ahead of print. PubMed PMID: 28506329 (accessed 12 December 2017). 
6. Marco CA, Larkin GL, Silbergleit R, et al. Filming of patients in academic emergency departments. Acad Emerg Med 2002;9(3):248-51.

7. Canadian Medical Protective Association. Smartphone recordings by patients: be prepared, it's happening. CMPA Perspect; 2017. Available at: https://www.cmpa-acpm.ca/sta tic-assets/pdf/advice-and-publications/perspective/com_17_ perspective_march-e.pdf (accessed 12 December 2017).

8. Saskatoon Health Region (SHR). Privacy and confidentiality policy \#7311-75-003; 2017. Available at: https://www.saska toonhealthregion.ca/about/RWPolicies/7311-75-003.pdf (accessed May 17, 2018).

9. Office of the Saskatchewan Information and Privacy Commissioner. Guidelines for arbitrators in Saskatchewan; 2016. Available at: https://oipc.sk.ca/assets/guidelines-for-arbi trators-in-saskatchewan.pdf (accessed May 17, 2018).

10. Campbell S, Sosa JA, Rabinovici R, et al. Do not roll the videotape: effects of the health insurance portability and accountability act and the law on trauma videotaping practices. Am 7 Surg 2006;191(2):183-90.

11. Hsieh P. Why you should record your doctor visits; 2015. Available at: http://www.forbes.com/sites/paulhsieh/2015 /02/16/why-you-should-record-your-doctor-visits/2/\#61665c 013d5c (accessed 12 December 2017).
12. Kwok E. Using my smartphone in hospital - but shh, don't tell (I'm recording). CanadiEM; 2013. Available at: https:// canadiem.org/using-my-smartphone-in-hospital-but-shhdont-tell/ (accessed 17 May 2018).

13. Blackwell $\mathrm{T}$. The latest trend in health care: patients secretly filming doctors; 2012. Available at: http://nationalpost.com/ news/canada/the-latest-trend-in-health-care-patients-secretlyfilming-doctors (accessed 17 May 2018).

14. Nolan B, Ackery A, Au B. What to do when a patient wants to record a patient-physician interaction in the emergency department; 2018. Available at: http://digitaleditions.sher idan.com/publication/?i=496804\#\{“issue_id":496804,"numpages":1,"page":154\} (accessed 18 May 2018).

15. Ellis RW. Examining the experience of performance anxiety and cognitive load by medical residents in simulation [dissertation]. Austin (TX): University of Texas at Austin 2016.

16. LaDonna K, Hatala R, Lingard L, et al. Staging a performance: learner's perceptions about direct observation during residency. Med Ed 2017;51:498-510.

17. CBC News. New province-wide health authority to be based in Saskatoon; 2017. Available at: http://www.cbc.ca/ news/canada/saskatoon/sask-health-authority-saskatoon-hq-1. 4104568 (accessed 12 December 2017). 